\title{
Ordu kent merkezi kamusal yeşil alanlarındaki odunsu bitkilerin su tüketimlerine ve ekolojik tolerans kriterlerine göre değerlendirilmesi
}

\author{
Mesut GÜZEL ${ }^{(D 1}$, Aysel ULUS ${ }^{(D}$ \\ 10rdu Üniversitesi, Ziraat Fakültesi Peyzaj Mimarlığı Bölümü, Ordu \\ 2İstanbul Üniversitesi-Cerrahpaşa, Orman Fakültesi Peyzaj Mimarlığı Bölümü, İstanbul
}

Alınıș tarihi: 27 Ağustos 2020, Kabul tarihi: 11 Mart 2021

Sorumlu yazar: Mesut GÜZEL, e-posta: mesutguzel@odu.edu.tr

\section{Öz}

Amaç: Bu çalışmada; Ordu kent merkezinde bulunan kamusal yeşil alanlardaki odunsu bitki taksonlarının, su tüketim düzeylerine ve ekolojik tolerans kriterlerine göre değerlendirilmesi amaçlanmıştır.

Materyal ve Yöntem: Ordu kent merkezinde yerleşimlerin yoğun olarak bulunduğu 21 mahalledeki kamusal yeşil alanlar ve bu alanlardaki odunsu bitkiler çalışmanın materyalini oluşturmaktadır. Çalışmada tespit edilen bitki taksonları; su tüketimleri bakımından "düşük", "düşük/orta", "orta”, "orta/yüksek" ve "yüksek" olmak üzere beş kategori altında sınıflandırılmıştır. Taksonların ekolojik tolerans düzeyleri her bir faktöre dayanımlarına göre "düşük toleranslı", "orta toleranslı" ve "yüksek toleranslı" olmak üzere üç sınıfa ayrılmıştır.

Araștırma Bulguları: Calıșmada; 44 familya ve 91 cinsten 150 farkl odunsu bitki taksonu tespit edilmiştir. Su tüketimi orta derecede olan bitkilerin oranı tüm bitkiler içerisinde $\% 46$ oranı ile en fazladır. Su tüketim düzeyi yüksek derecede olan bitkilerin oranı mezarlık alanlarında en fazla iken düşük su tüketimine sahip bitkilerin oranı koruluk ve mesire alanlarında en fazla durumdadır. Tespit edilen bitki taksonlarının büyük çoğunluğu dona, kirliliğe ve rüzgâra karşı yüksek toleranslı iken kuraklığa orta derecede toleranslıdır.

Sonuç: Yapılan bu çalıșma ile; Ordu kent merkezi kamusal yeşil alanlarındaki odunsu bitki taksonları, su tüketimlerine ve ekolojik tolerans kriterlerine göre ortaya konmuştur. Ordu kenti yeşil alanlarında yapılacak olan bitkilendirme çalışmalarında, bitkilerin estetik-görsel değerleri ile kente ekolojik yönden uyumları birlikte düşünülmelidir. Su tüketimi düşük düzeyde olan, yörede doğal yayılış gösteren ve kentteki ekstrem ekolojik şartlara toleranslı bitki türlerinin tercih edilmesi peyzaj uygulamalarının başarısını arttıracak ve sürdürülebilir yeşil alanlar oluşturulmasına katkı sağlayacaktır.

Anahtar kelimeler: Kamusal Yeşil Alan; Odunsu Bitki; Ekolojik Tolerans; Su Tüketimi; Ordu

Evaluation of woody plants in public green spaces in Ordu city center according to water consumption and ecological tolerance criteria

\begin{abstract}
Objective: The study aims to evaluate the woody plant taxa in public green areas in the city center of Ordu according to water consumption levels and ecological tolerance criteria.
\end{abstract}

Materials and Methods: Public green spaces in 21 neighborhoods where settlements are densely located in Ordu city center and woody plants in these areas constitute the material of the study. Plant taxa determined in the study; in terms of water consumption, it is classified under five categories: "low", "low / medium", "medium", "medium / high" and "high". The ecological tolerance levels of taxa are divided into three classes as "low tolerant", "medium tolerant" and "high tolerant" according to their resistance to each factor.

Results: In the study, 150 different woody plant taxa from 44 families and 91 genera were identified. The 
rate of plants with moderate water consumption is the highest with $46 \%$ of all plants. The proportion of plants with a high level of water consumption is highest in cemetery areas, while the rate of plants with low water consumption is highest in groves. The majority of the plant taxa identified are highly tolerant to frost, air pollution and wind, while moderately drought tolerant.

Conclusion: With this study, woody plant taxa in Ordu city center public green areas were revealed according to water consumption and ecological tolerance criteria. In the plantation to be carried out in the green areas of the city of Ordu, the aestheticvisual values of the plants and their ecological adaptation to the city should be considered together. Choosing plant species with low water consumption, natural distribution in the region and tolerant of extreme ecological conditions in the city will increase the success of landscape applications and contribute to the creation of sustainable green areas.

Key words: Public Green Spaces; Woody Plant; Ecological Tolerance; Water Consumption, Ordu

\section{Giriş}

Dünya nüfusunun kontrolsüz artışı, küresel ısınma ve su kaynaklarının bilinçsizce tüketilmesi suyu ve su kullanımını bulunduğumuz yüzyılın en önemli sorunlarından biri haline getirmiștir (Bayramoğlu ve diğ., 2013). Özellikle iklim değişikliği, dünya genelinde yaşanan kuraklığın şiddetini ve sıklığını arttırmaktadır. Gıda ve Tarım Örgütü, son 40 yılda neredeyse tüm bölgelerde görülen kuraklığın, insanları diğer doğa felaketlerinden daha fazla etkilediğini ifade etmektedir (FAO, 2017). Peyzaj uygulamalarında bilinçsiz su tüketiminin önüne geçmeyi hedefleyen ekolojik peyzaj tasarımı yaklaşımlarında açı-yeşil alanların sürdürülebilirliği noktasında suyun önemi büyüktür (Zencirkıran ve Akdeniz, 2017). Bu sebeple düzenlemelerde tercih edilen bitki türlerinin su isteklerinin iyi bilinmesi gerekmektedir.

$\mathrm{Bu}$ çalıșmanın temel amacl; Ordu kent merkezi kamusal yeşil alanlarındaki odunsu bitki taksonlarının belirlenerek su tüketim düzeylerine ve ekolojik tolerans kriterlerine göre değerlendirilmesidir. Hızla kentleşen Ordu'da giderek önemli hale gelen yeşil alanların sürdürülebilirliği noktasında bu alanlardaki bitki materyalinin ekolojik özelliklerinin belirlenmesi gelecekte yapılacak tasarım ve uygulamaların doğru şekilde yapılmasına katkı sağlayacaktır. Çalışma; Ordu kent merkezinde yer alan kamusal açık-yeşil alanları ve bu alanlardaki ağaç, ağaççık, çalı ve sarılıcı formlardaki odunsu bitki taksonlarını kapsamaktadır. Özel ve yarı-özel açık-yeşil alanlar ile otsu özellikteki bitki taksonları çalışmanın kapsamına dâhil edilmemiştir.

Ordu kent merkezi kamusal açık-yeşil alanlarında, doğrudan odunsu bitki taksonlarının belirlenmesi ve ekolojik tolerans kriterlerine göre değerlendirilmesi üzerine yapılmış herhangi bir çalışma bulunmamaktadır. Bu anlamda böyle bir çalışmanın yapılması gelecekte kentin diğer açık-yeșil alanlarında yapılacak çalışmalar için bir altlık oluşturacaktır.

\section{Materyal ve Yöntem}

Araştırma alanı olarak; Ordu ili Altınordu ilçesi sınırları içerisinde, kent merkezinde yer alan ve yoğun yerleşimlerin bulunduğu 21 mahalle seçilmiştir (Şekil 1). $40^{\circ} 55^{\prime}$ ve $41^{\circ} 01^{\prime}$ kuzey enlemleri ile $37^{\circ} 49^{\prime}$ ve $37^{\circ} 58^{\prime}$ doğu boylamları arasında yer alan araştırma alanının yaklaşık büyüklüğü 2.600 ha'dır. Belirlenen bu alanın sınırları içerisinden örneklenen kamusal yeşil alanlarda bulunan odunsu bitki taksonları çalışmanın materyalini olușturmuștur. Seçilen 32 örnek alanın 11'i bulvar, cadde, refüj ve kavşak düzenlemesi; 4'ü sahil parkı; 9'u mahalle parkı; 5'i mezarlık; 3'ü koruluk ve mesire alanıdır. Bu alanlarda tespit edilen odunsu bitki taksonları su tüketimleri ve ekolojik faktörlere karşı tolerans düzeylerine göre değerlendirilmiştir.

Araştırma alanının içerisinde yer aldığı Ordu ilinde tipik bir Karadeniz iklimi hâkimdir. Bu iklim tipinin doğal bitki örtüsünü, kıyılarda geniş yapraklı ve nemli ormanlar ile yüksek kesimlerde soğuk ve nemli şartlarda gelişim gösteren iğne yapraklı ormanlar oluşturur (Sensoy ve ark., 2008). Ordu iline ait 1959 ve 2019 yılları arasındaki 60 yıllık dönemin iklim istatistiklerine göre oluşturulan Walter iklim diyagramı Şekil 2'de görülmektedir. Buna göre; ildeki yıllık ortalama sıcaklık $14.4{ }^{\circ} \mathrm{C}$ ve yıllık ortalama yağış miktarı 1045.2 mm'dir. Yılın hiçbir döneminde toprakta su açığı bulunmamaktadır (Şekil 2). Thornthwaite iklim sınıflandırmasına göre ise Ordu ilinin iklim özellikleri nemli, 2.derece mezotermal ve su noksanı yaz mevsiminde-orta derecededir (MGM, 2019).

Ordu ili fitocoğrafik olarak Türkiye için Karadeniz kıyılarına karşıllı gelen Avrupa-Sibirya floristik bölgesinde yer almaktadır (Deveci ve ark., 2012; 
Özbucak ve ark., 2006). Avrupa-Sibirya flora bölgesi, Ordu'nun en önemli akarsuyu olan Melet Irmağı'nın doğal sınır olușturduğu iki alt floraya ayrılır. Melet Irmağı'nın doğusunda kalan alana "Kolşik flora" alanı, batısında bulunan alana ise "Öksin flora" alanı denir. Doğudaki kolşik flora alanı, batıdaki öksin flora alanından daha fazla yağış aldığından flora bakımından daha zengindir (Baş, 2014). İl sınırları içerisinde tespit edilen 22'si endemik, toplam 309 bitki taksonu bulunmaktadır (TÜBIVES, 2019).

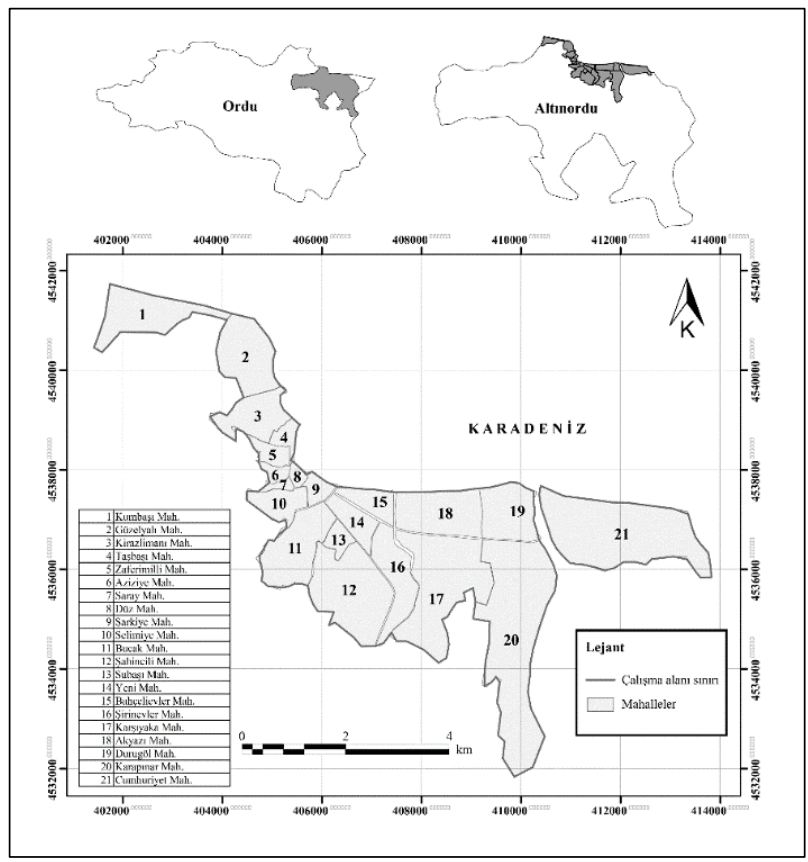

Şekil 1. Araştırma alanının konumu

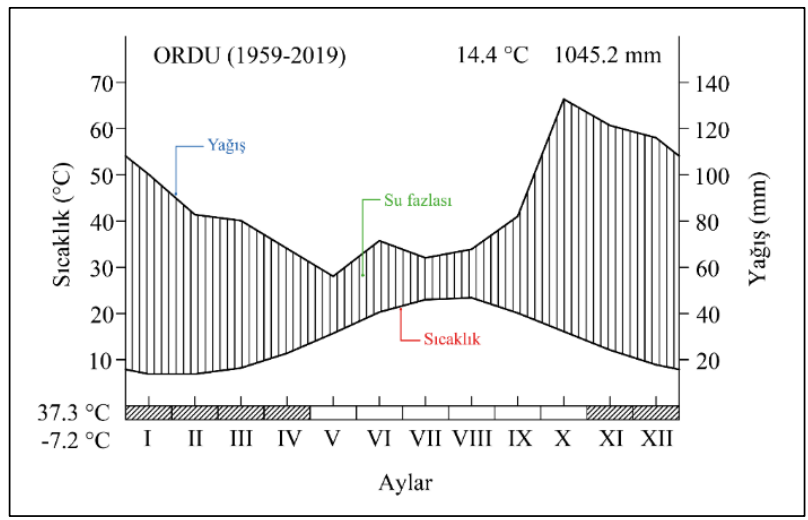

Şekil 2. Walter ve ark. (1975) yöntemine göre oluşturulan Ordu ili iklim diyagramı

Kamusal yeşil alanlardaki odunsu bitkilerin tespit edilmesi amaciyla 2019 yllında vejetasyonun aktif olduğu Nisan-Eylül ayları arasında arazi çalışmaları gerçekleştirilmiştir. Örnek alanlar belirli aralıklarla ziyaret edilerek odunsu bitki türleri analiz ve değerlendirmede kullanılmak üzere teşhis edilerek kaydedilmiştir (Dirr, 2002; Dirr, 2011; Farjon, 2017; Ouden ve Boom, 1982; Yener, 2012).

Çalışmada tespit edilen odunsu bitki taksonlarının ekolojik özelliklerine göre değerlendirilmesinde Zencirkıran ve Akdeniz'in (2017) uyguladığı yöntem benimsenmiştir. Buna göre; odunsu bitki taksonlarının su tüketimleri ve ekolojik tolerans düzeyleri (dona, ısıya, kuraklığa, tuzluluğa, kirliliğe ve rüzgâra dayanıklılık) çeşitli kaynaklardan yararlanılarak belirlenmiş ve tablo biçiminde Ek 1'de sunulmuştur (Çepel, 1988; Dirr, 2011; Genç, 2007; Anonim, 2020a; Anonim, 2020b; Anonim, 2020c; Anonim, 2020e; Anonim, 2020e; Anonim, 2020f; Yener ve Güzel, 2019; Yener ve ark., 2020; Zencirkıran, 2013). Tespit edilen taksonlar; su tüketimleri bakımından "düşük", "düşük/orta", "orta", "orta/yüksek" ve "yüksek" olmak üzere beş kategori altında sınıflandırılmıştır. Ayrıca taksonların ekolojik tolerans düzeyleri her bir faktöre dayanımlarına göre " 1 = düşük toleranslı", "2 = orta toleranslı" ve "3 = yüksek toleranslı" olmak üzere üç sınıfa ayrılmıștır.

\section{Bulgular}

Arazi çalıșmaları sonucunda, 32 örnek alanda 44 familya ve 91 cinsten toplam 150 farklı odunsu bitki taksonu tespit edilmiștir. Bunların \%79.9'u kapalı tohumlu (Angiospermae) ve \%20.1'i açık tohumlu (Gymnospermae) alt grubundandır. Bitkilerin kökenlerine bakıldığında \%64'ünün egzotik ve \%36'sının doğal olduğu görülmüștür. Taksonların ait olduğu familyalara göre yapılan değerlendirmede en fazla takson içeren familyanın $\% 12$ ile Rosaceae familyası olduğu tespit edilmiştir. Bunu sırasiyla Cupressaceae (\%11), Sapindaceae (\%8), Pinaceae (\%7), Oleaceae (\%6) ve Leguminosae (\%5) familyaları izlemektedir. Tüm taksonlar içerisindeki oranı $\% 3$ ve altında olan toplam 38 diğer familya bulunmaktadır.

Tüm alanlarda su tüketim düzeyi orta derecede olan taksonlar en yüksek oranda (\%46) bulunmaktadır. Bunu sırasıyla su tüketimleri düşük/orta (\%28.2), orta/yüksek (\%10.5), düşük (\%9.7) ve yüksek (\%5.6) olan bitkiler takip etmektedir (Şekil 3).

Bulvar ve cadde düzenlemelerinde su tüketimi düşük taksonların oranı \%11.5 ve yüksek taksonların oranı \%9.1 iken bitkilerin \%50'si orta derecede su tüketimine sahip durumdadır. Sahil parklarında orta derecede su tüketimi olan bitkilerin oranı $\% 47.8^{\prime}$ dir. Mahalle parklarında su tüketimi yüksek olan 
taksonların oranı diğer yeşil alan türlerine göre düşük düzeydedir. Su tüketim düzeyi yüksek derecede olan bitkilerin oranı \%9.7 ile mezarlık alanlarında en fazla iken düșük su tüketimine sahip bitkilerin oranı \%13 ile koruluk ve mesire alanlarında en fazla durumdadır. Tüm yeşil alan türlerinde ise orta derecede su tüketimine sahip takson oranı daha fazladır (Çizelge 1).

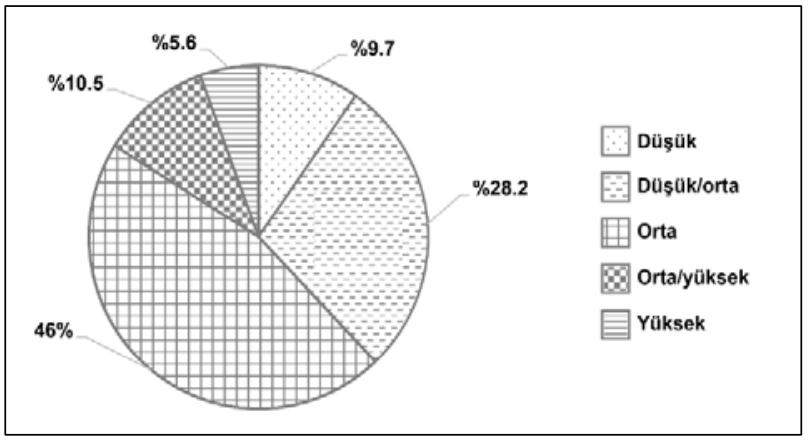

Şekil 3. Çalışmada tespit edilen odunsu bitki taksonlarının su tüketimine göre dağılımı
Odunsu bitki taksonlarının çeşitli çevresel faktörlere karşı toleranslarını belirlemek amacıyla yapılan değerlendirmede; taksonlarının \%68.6'sının dona ve \%67.9'unun rüzgâra karşı yüksek toleranslı olduğu görülmüştür. Ancak bitkilerin \%45'inin tuzluluğa ve \%45.3'ünün ise ssıya olan toleransı düşüktür. Bitkilerin oldukça büyük bir kısmı (\%85.2) hava kirliliğine karşı yüksek toleranslıdır. Yine bitkilerin yaklaşık \%78'i kuraklığa orta ve yüksek derecelerde tolerans gösteren türlerden oluşmuştur (Şekil 4).

Bitkilerin çeşitli çevresel faktörlere karşı toleransları açık-yeşil alan türlerine göre değerlendirildiğinde; bulvar ve cadde düzenlemelerinde tespit edilen taksonların \%71.4'ünün dona, \%84.6'sının hava kirliliğine ve \%62.6'sının rüzgâra karşı yüksek toleranslı olarak bulunmuştur. Tüm açık-yeşil alanlardaki bitki taksonları büyük oranda dona karşı yüksek toleranslı bulunmuştur. Koruluk ve mesire alanları dışındaki tüm alanlarda kuraklığa toleransı orta düzeyde olan bitki türleri çoğunluktadır (Çizelge 2).

Çizelge 1. Su tüketim oranlarının yeşil alan türüne göre dağılımı

\begin{tabular}{cccccc}
\hline \multirow{2}{*}{ Yeşil alan* } & \multicolumn{3}{c}{ Su tüketimi (\%) } \\
\cline { 2 - 5 } & Düşük & Düşük/orta & Orta & Orta/yüksek \\
\hline BC & 11.5 & 25.5 & 50.0 & 3.8 & 9.0 \\
SP & 9.0 & 28.4 & 47.8 & 9.1 \\
MP & 12.5 & 24.3 & 48.6 & 10.4 & 8.0 \\
MZ & 9.7 & 27.4 & 45.2 & 4.2 & 9.1 \\
KM & 13.0 & 21.7 & 52.2 & 4.4 \\
\hline
\end{tabular}

*BC: Bulvar, cadde, refüj ve kavşak düzenlemeleri, SP: Sahil parkları, MP: Mahalle parkları, MZ: Mezarlıklar, KM: Koruluk ve mesire alanları.

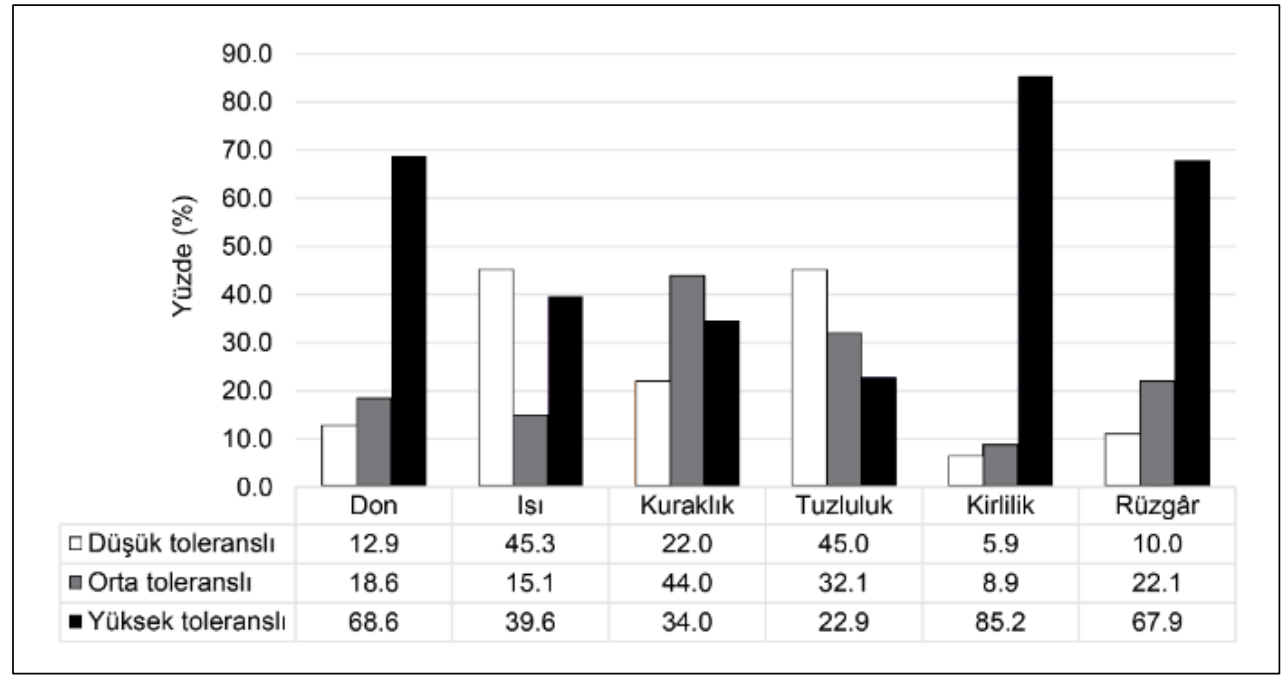

Şekil 4. Çalışmada tespit edilen odunsu bitki taksonlarının su tüketimine göre dağılımı 
Çizelge 2. Tolerans oranlarının yeşil alan türüne göre dağılımı

\begin{tabular}{|c|c|c|c|c|c|c|}
\hline Tolerans faktörü & Tolerans düzeyi* & $\mathrm{BC}^{* *}$ & SP & MP & $\mathrm{MZ}$ & KM \\
\hline \multirow{3}{*}{ Don } & 1 & $13.2^{* * *}$ & 14.9 & 14.1 & 14.6 & 26.3 \\
\hline & 2 & 15.4 & 18.8 & 17.9 & 14.6 & 5.3 \\
\hline & 3 & 71.4 & 66.3 & 67.9 & 70.7 & 68.4 \\
\hline \multirow{3}{*}{ Isı } & 1 & 44.0 & 45.5 & 47.4 & 51.2 & 57.9 \\
\hline & 2 & 13.2 & 16.8 & 11.5 & 12.2 & 0.0 \\
\hline & 3 & 42.9 & 37.6 & 41.0 & 36.6 & 42.1 \\
\hline \multirow{3}{*}{ Kuraklık } & 1 & 23.1 & 19.8 & 21.8 & 19.5 & 36.8 \\
\hline & 2 & 41.8 & 41.6 & 44.9 & 46.3 & 26.3 \\
\hline & 3 & 35.2 & 38.6 & 33.3 & 34.1 & 36.8 \\
\hline \multirow{3}{*}{ Tuzluluk } & 1 & 44.0 & 43.6 & 44.9 & 46.3 & 47.4 \\
\hline & 2 & 36.3 & 35.6 & 33.3 & 39.0 & 31.6 \\
\hline & 3 & 19.8 & 20.8 & 21.8 & 14.6 & 21.1 \\
\hline \multirow{3}{*}{ Kirlilik } & 1 & 7.7 & 5.0 & 7.7 & 12.2 & 5.3 \\
\hline & 2 & 7.7 & 5.0 & 9.0 & 4.9 & 15.8 \\
\hline & 3 & 84.6 & 90.1 & 80.8 & 82.9 & 78.9 \\
\hline \multirow{3}{*}{ Rüzgâr } & 1 & 11.0 & 10.9 & 7.7 & 7.3 & 10.5 \\
\hline & 2 & 26.4 & 19.8 & 24.4 & 22.0 & 5.3 \\
\hline & 3 & 62.6 & 69.3 & 67.9 & 70.7 & 84.2 \\
\hline
\end{tabular}

*1: Düşük toleranslı, 2: Orta toleranslı, 3: Yüksek toleranslı.

**BC: Bulvar, cadde, refüj ve kavşak düzenlemeleri, SP: Sahil parkları, MP: Mahalle parkları, MZ: Mezarlıklar, KM: Koruluk ve mesire alanları.

*** Değerler yüzde (\%) olarak ifade edilmiştir.

\section{Tartışma}

Yaşadığımız yüzyılın en önemli sorunlarından biri kullanılabilir ve nitelikli su miktarının azalması sonucu yaşanan su kıtlığıdır. Nüfus artışına bağlı olarak gelişen hızlı ve plansız kentleşmenin, yoğun tarım ve sanayi faaliyetlerinin, yanlış arazi kullanımlarının ve küresel iklim değișikliğinin bu durumun oluşmasındaki payı büyüktür (Karadağ, 2008). Bir ülkenin su zengini sayllabilmesi için kişi başına düşen yıllık kullanılabilir su miktarının 8.000$10.000 \mathrm{~m}^{3}$ arası olması gerekir. Türkiye'de kişi başına düşen yıllık kullanılabilir ve nitelikli su miktarı yaklaşık $1.300 \mathrm{~m}^{3}$ 'tür (Anonim, 2016). Bu yönüyle Türkiye aslında "su fakiri" bir ülke konumundadır. Bu nedenle Türkiye'de su kaynaklarının etkin kullanımı tüm Dünya'da olduğu gibi gittikçe önem kazanmaktadır (Bayramoğlu ve Demirel, 2014). Suyun yoğun olarak kullanıldı̆̆ alanlardan biri de peyzaj düzenlemeleridir. Kamusal yeşil alanlarda tespit edilen odunsu bitki taksonlarının \%62.1'inin su tüketimi orta ve üzeri düzeydedir. Bu tip alanlarda su gereksinimi daha az olan, kuraklığa dayanıklı ve yabancı yurtlu bitkiler yerine doğal türlerin kullanılması gerekmektedir (Çetin ve Mansuroğlu, 2018).

Denize yakın olmaları sebebiyle yoğun şekilde tuzluluğa maruz kalan sahil parklarında yapılacak olan peyzaj düzenlemelerinde tuzluluğa karşı toleranslı türlerin tercih edilmesi gerekir. Tuzluluk, bitkilerin topraktaki suyu almasını zorlaştıran ve bitki gelişimini olumsuz etkileyen unsurlardan biridir (Ekmekçi ve ark., 2005). Çalışma kapsamında incelenen sahil parklarındaki bitki taksonlarının \%79.2'sinin tuzluluk toleransı orta ve düșük düzeydedir. Tuzluluk etkisindeki bu tip alanlarda Elaeagnus angustifolia, Laurocerasus officinalis, Nerium oleander, Pinus pinaster, Tamarix sp. gibi tuzluluk toleransı orta ve yüksek düzeyde olan türlerin daha fazla tercih edilmesi isabetli olacaktır.

Kentlerdeki bitki varlığının, hava kirliliğini büyük oranda ortadan kaldırarak kentsel hava kalitesini arttırdığı bilinmektedir (Nowak ve ark., 2006). Ancak bazı kirlilik toleransı düşük bitkilerin tercih edilmesi ya da bitkinin tolere edebileceğinden çok daha fazla kirliliğe maruz kalması sonucunda çeşitli zararlı etkiler ortaya çıkabilmektedir. Hava kirleticilerinin ve zararlı partikül yoğunluğunun en fazla olduğu alanların başında bulvar ve caddeler gelmektedir. Karadeniz Sahil Yolu'nun Ordu ili sınırları içerisindeki bölümünde yapılan bir araştırmada mevcut trafik yoğunluğunun bitkilerde ağır metal kirliliği yarattığı sonucuna ulaşılmıştır (Atabeyoğlu ve ark., 2016). Örnek alanlarda tespit edilen bitkilerin büyük çoğunluğu (\%84.6) kirliliğe karşı yüksek tolerans göstermektedir. İncelenen bulvar ve cadde düzenlemelerinde sıkça karşılaşılan 
Acer saccharinum, Robinia pseudoacacia 'Umbraculifera', Platanus orientalis gibi ağaç taksonlarının kirlilik toleransları yüksek düzeydedir. Ancak Mustafa Kemal Bulvarı ve Zübeyde Hanım Caddesi gibi örnek alanlarda hava kirliliğine karşı toleransı oldukça düşük olan ve alttan dallanan yapısı ile yol ağacı olarak kullanılmaya uygun olmayan Cedrus deodora'nın birey bazında çok sayıda kullanıldığı görülmüştür. Cedrus sp., Picea sp., Abies sp. gibi hassas türlerin hava kirliliğine maruz kalan alanlarda tercih edilmemesi yerinde olacaktır (Ürgenç, 1998).

\section{Sonuç}

Ordu kenti; büyükşehir olmasıyla birlikte ivmesi giderek artan bir hızla güney ve doğu yönlerinde gelișim göstermektedir. $\mathrm{Bu}$ hızlı kentleșmenin sonucu olarak yeșil alanlar giderek önem kazanmaktadır. Yeşil alanların büyüklüğü ve sayısı kadar, bu alanlarda seçilen bitki türleri de önemsenmelidir. Bitki türlerinin su tüketimlerinin ve ekolojik koşullara toleranslarının bilinerek seçilmesi, kente olan uyumlarını arttıracaktır. Yapılan bu çalışma ile; Ordu kent merkezi kamusal yeşil alanlarındaki odunsu bitki taksonları, su tüketimlerine ve ekolojik tolerans kriterlerine göre ortaya konmuştur. Ordu kenti yeşil alanlarında yapılacak olan bitkilendirme çalışmalarında, bitkilerin estetik-görsel değerleri ile kente ekolojik yönden uyumları birlikte düşünülmelidir. $\mathrm{Su}$ tüketimi düşük düzeyde olan, yörede doğal yayılış gösteren ve kentteki ekstrem ekolojik şartlara toleranslı bitki türlerinin tercih edilmesi peyzaj uygulamalarının başarısını arttıracak ve sürdürülebilir yeșil alanlar oluşturulmasına katkı sağlayacaktır.

\section{Ekler}

Ek 1. Çalışmada tespit edilen bitki taksonları ve ekolojik tolerans kriterlerine göre değerlendirilmesi (1=Düşük toleranslı, 2=0rta toleranslı, 3=Yüksek toleranslı).

\begin{tabular}{|c|c|c|c|c|c|c|c|c|c|c|c|c|c|c|c|c|c|c|}
\hline \multirow{3}{*}{ Taksonlar } & \multicolumn{18}{|c|}{ Ekolojik tolerans kriterleri } \\
\hline & \multicolumn{3}{|c|}{ Don } & \multicolumn{3}{|c|}{ Isl } & \multicolumn{3}{|c|}{ Kuraklık } & \multicolumn{3}{|c|}{ Tuzluluk } & \multicolumn{3}{|c|}{ Kirlilik } & \multicolumn{3}{|c|}{ Rüzgâr } \\
\hline & 1 & 2 & 3 & 1 & 2 & 3 & 1 & 2 & 3 & 1 & 2 & 3 & 1 & 2 & 3 & 1 & 2 & 3 \\
\hline Abelia $\times$ grandiflora & & & $\bullet$ & & $\bullet$ & & & $\bullet$ & & $\bullet$ & & & & & $\bullet$ & & & $\bullet$ \\
\hline Abelia x grandiflora 'Kaleidoscope' & & & • & & & $\bullet$ & & $\bullet$ & & $\bullet$ & & & & & $\bullet$ & & & $\bullet$ \\
\hline Abies concolor & & & $\bullet$ & • & & & & $\bullet$ & & $\bullet$ & & & & $\bullet$ & & & & $\bullet$ \\
\hline Abies nordmanniana & & & $\bullet$ & $\bullet$ & & & & $\bullet$ & & $\bullet$ & & & $\bullet$ & & & & & $\bullet$ \\
\hline Acacia dealbata & $\bullet$ & & & - & & & & & $\bullet$ & $\bullet$ & & & & & $\bullet$ & & $\bullet$ & \\
\hline Acer buergerianum & & & $\bullet$ & $\bullet$ & & & & & $\bullet$ & & & $\bullet$ & & & $\bullet$ & & & $\bullet$ \\
\hline Acer campestre & & & $\bullet$ & $\bullet$ & & & & $\bullet$ & $\bullet$ & & $\bullet$ & & & & $\bullet$ & & & $\bullet$ \\
\hline Acer negundo & & & $\bullet$ & $\bullet$ & & & & $\bullet$ & & $\bullet$ & & & & & $\bullet$ & $\bullet$ & & \\
\hline Acer negundo 'Flamingo' & & & $\bullet$ & $\bullet$ & & & & $\bullet$ & & & $\bullet$ & & & $\bullet$ & & $\bullet$ & & \\
\hline Acer negundo 'Variegatum' & & & $\bullet$ & $\bullet$ & & & & $\bullet$ & & & $\bullet$ & & & $\bullet$ & & $\bullet$ & & \\
\hline Acer palmatum & & & $\bullet$ & $\bullet$ & & & $\bullet$ & & & & $\bullet$ & & & $\bullet$ & & & & $\bullet$ \\
\hline Acer palmatum 'Atropurpurea' & & & $\bullet$ & $\bullet$ & & & $\bullet$ & & & & $\bullet$ & & & $\bullet$ & & & & $\bullet$ \\
\hline Acer platanoides 'Crimson King' & & $\bullet$ & & & $\bullet$ & & & $\bullet$ & & & & $\bullet$ & & & $\bullet$ & & & $\bullet$ \\
\hline Acer pseudoplatanus & & & $\bullet$ & $\bullet$ & & & $\bullet$ & & & $\bullet$ & & & & & $\bullet$ & & & $\bullet$ \\
\hline Acer saccharinum & $\bullet$ & & & & & $\bullet$ & & & $\bullet$ & & $\bullet$ & & & & $\bullet$ & $\bullet$ & & \\
\hline Acer saccharum & & & $\bullet$ & & & $\bullet$ & & $\bullet$ & & $\bullet$ & & & & & & $\bullet$ & & \\
\hline Aesculus hippocastanum & & & $\bullet$ & & & $\bullet$ & $\bullet$ & & & $\bullet$ & & & & $\bullet$ & & $\bullet$ & & \\
\hline Agave americana & $\bullet$ & & & & & $\bullet$ & & & $\bullet$ & & & $\bullet$ & & & $\bullet$ & & & $\bullet$ \\
\hline Albizia julibrissin & & & $\bullet$ & & & $\bullet$ & & $\bullet$ & & $\bullet$ & & & & & $\bullet$ & & & $\bullet$ \\
\hline Alnus glutinosa & & & $\bullet$ & $\bullet$ & & & $\bullet$ & & & $\bullet$ & & & & & $\bullet$ & & & $\bullet$ \\
\hline Berberis julianae & & & $\bullet$ & $\bullet$ & & & $\bullet$ & & & $\bullet$ & & & & & $\bullet$ & & & $\bullet$ \\
\hline Berberis thunbergii 'Atropurpurea' & & & $\bullet$ & $\bullet$ & & & & $\bullet$ & & $\bullet$ & & & & & $\bullet$ & & & $\bullet$ \\
\hline Betula pendula & & $\bullet$ & & & & $\bullet$ & & & $\bullet$ & & $\bullet$ & & & & $\bullet$ & & & $\bullet$ \\
\hline Betula pendula 'Youngii' & & $\bullet$ & & & & & & $\bullet$ & & & $\bullet$ & & & & $\bullet$ & & & $\bullet$ \\
\hline Buddleja davidii & & & $\bullet$ & $\bullet$ & & & $\bullet$ & & & $\bullet$ & & & & & $\bullet$ & & & $\bullet$ \\
\hline Buxus sp. & & & $\bullet$ & & & $\bullet$ & & $\bullet$ & & & $\bullet$ & & & & $\bullet$ & & & $\bullet$ \\
\hline Carpinus betulus & & & $\bullet$ & • & & & & & • & • & & & & & • & & & • \\
\hline Catalpa bignonioides & & & $\bullet$ & $\bullet$ & & & • & & & $\bullet$ & & & & & $\bullet$ & & & • \\
\hline Cedrus atlantica 'Glauca' & & & $\bullet$ & $\bullet$ & & & & $\bullet$ & & $\bullet$ & & & & & $\bullet$ & & & $\bullet$ \\
\hline
\end{tabular}


Ek 1. Calıșmada tespit edilen bitki taksonları ve ekolojik tolerans kriterlerine göre değerlendirilmesi (1=Düşük toleranslı, 2=Orta toleranslı, 3=Yüksek toleranslı).(Devamı)

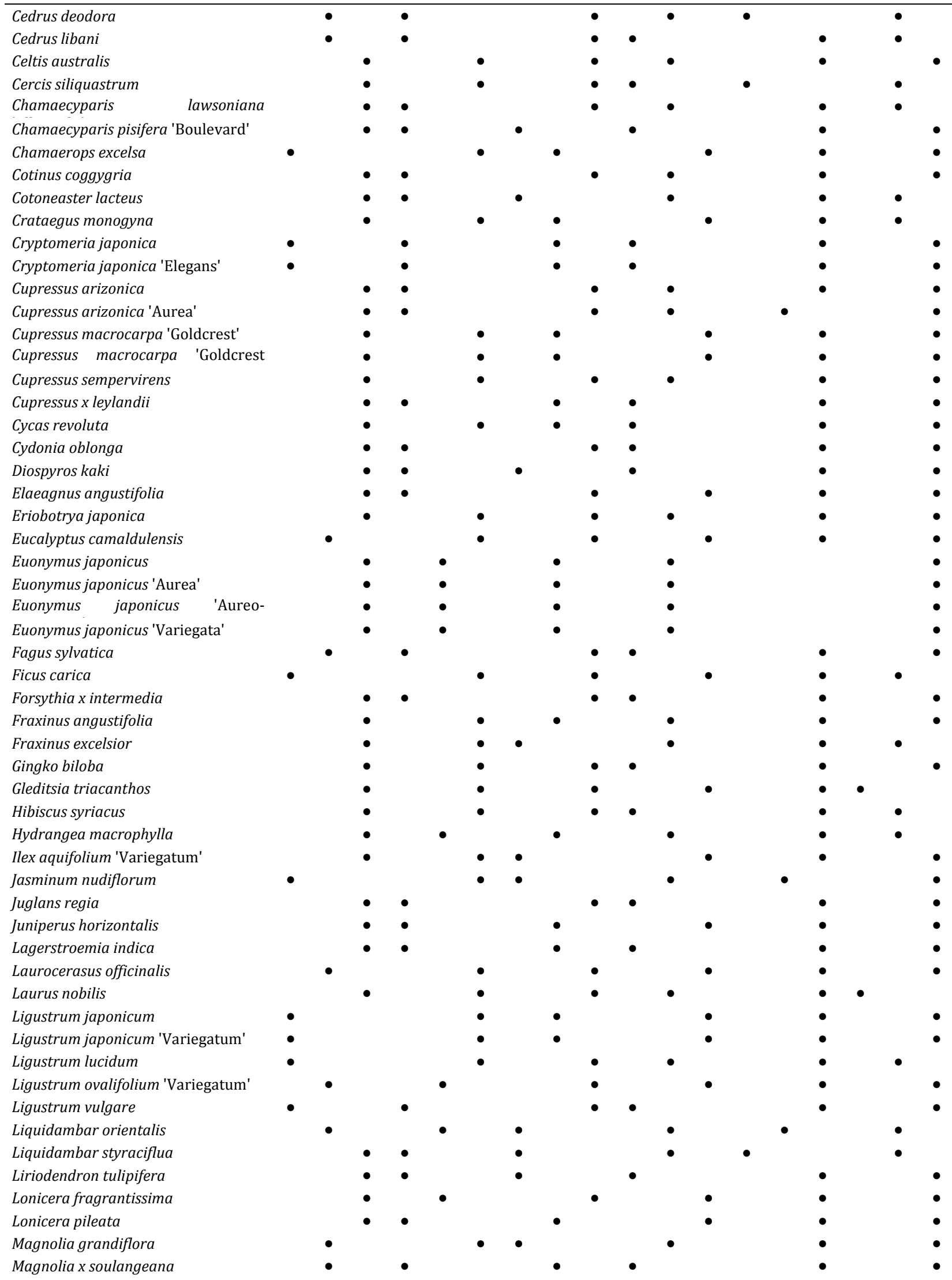


Ek 1. Çalışmada tespit edilen bitki taksonları ve ekolojik tolerans kriterlerine göre değerlendirilmesi (1=Düşük toleranslı, 2=Orta toleranslı, 3=Yüksek toleranslı).Devamı

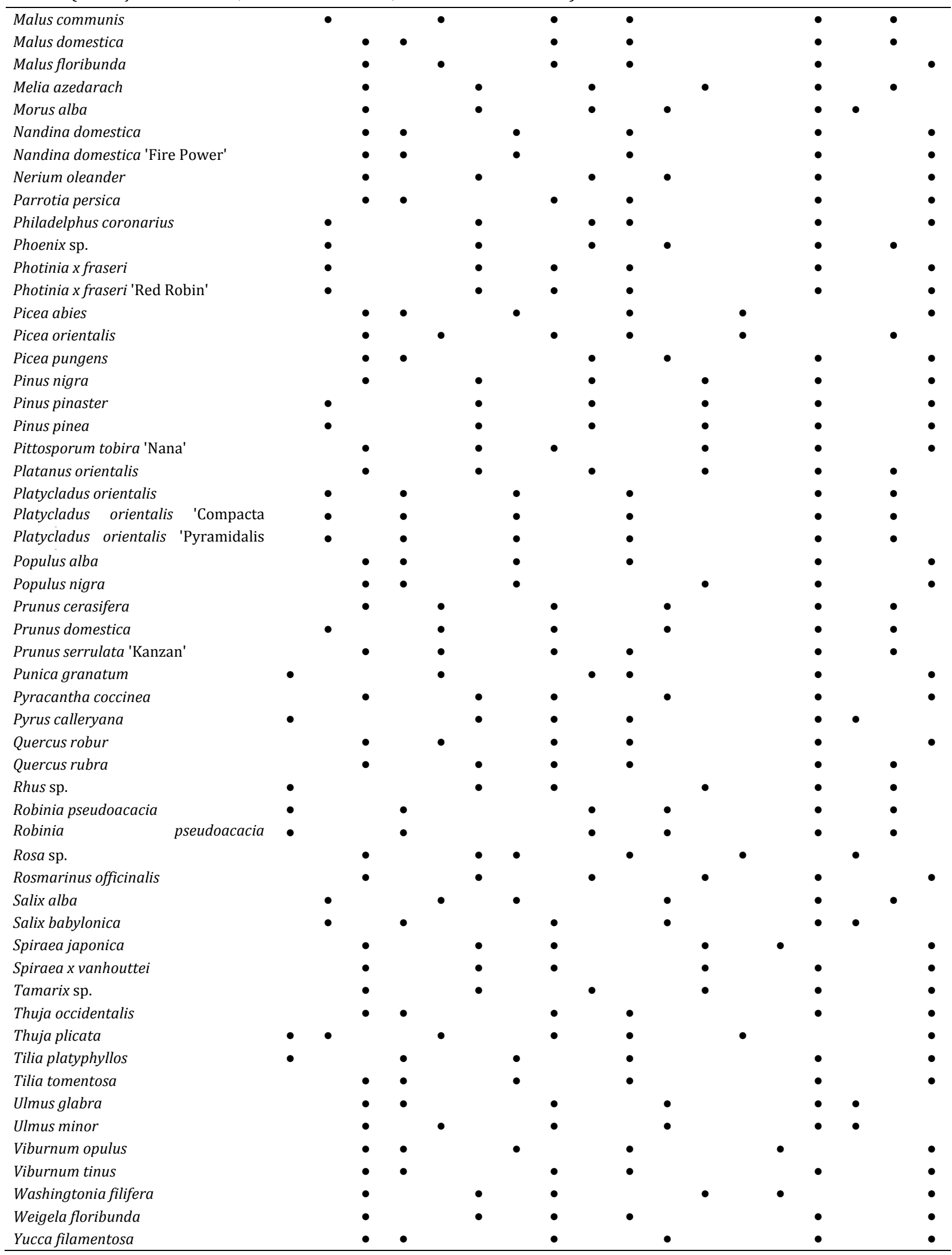




\section{Çıkar çatışması}

Yazarlar arasında herhangi bir çıkar çatışması yoktur.

\section{Yazarların katkı beyanı}

MG: Detaylı literatür taraması, veri toplama-işleme, analiz-yorum ve metin yazma aşamalarına katkıda bulunmuştur. AU: Çalışma tasarımı, yöntemin oluşturulması, danıșmanlık ve eleştirel inceleme așamalarına katkıda bulunmuștur.

\section{Teşekkür}

Bu çalışma; Dr. Öğr. Üyesi Aysel ULUS danıșmanlığında yürütülen ve Mesut GÜZEL tarafından hazırlanan "Ordu Kent Merkezi Kamusal Açık-Yeşil Alanlarındaki Odunsu Bitki Türleri Üzerine Bir Araştırma” isimli yüksek lisans tezinden üretilmiștir.

\section{Kaynaklar}

Anonim, (2016). İklim Değişikliğinin Su Kaynaklarına Etkisi Projesi Nihai Raporu, T.C. Orman ve Su İşleri Bakanlığı Su Yönetimi Genel Müdürlügü, Ankara.

Anonim, (2020a). University of Illinois Extensions. "Shrubs by Tolerance", https://web.extension.illinois.edu /shrubselector/sort.cfm?fn=tolerance, [Erişim tarihi: 28 Mart 2020].

Anonim, (2020b). https://watereuse.org/salinitymanagement/cp/cp_7_table-2.html, [Erişim tarihi: 06.02.2020].

Anonim, (2020c). https://gardening.yardener.com/SaltTolerance-By-Tree-Species, [Erişim tarihi: 06.01.2020].

Anonim, (2020d). https://gardening.yardener.com/SaltTolerance-By-Shrub-Species, [Erişim tarihi: 08.01.2020].

Anonim, (2020e). AUB Landscape Plant Database, https://landscapeplants.aub.edu.lb, [Erişim tarihi: 06.01.2020].

Anonim, (2020f). https://harlowgardens.com/salttolerant-plants, [Erişim tarihi: 06.04.2020].

Atabeyoğlu, Ö., Yeșil, P., \& Yeșil, M., (2016). Assessment of highway-induced pollution through plant and soil analyses, in case of Ordu city section of Black Sea Coastal Highway. Fresenius Environmental Bulletin. 25 (10), 4261-4268.

Baş, M., (2014). İlkçağ’dan Günümüze Ordu Tarihi, Yason Yayınları, Ankara.

Bayramoğlu, E., Ertek, A., \& Demirel, Ö., (2013). Su tasarrufu amacıyla peyzaj mimarlığı uygulamalarında kısıntılı sulama yaklaşımı. Inönü Üniversitesi Sanat ve Tasarım Dergisi, 3 (7), 45-53.

Bayramoğlu, \& E., Demirel, Ö., (2014). Peyzaj alanlarında kullanılan Berberis thunbergii 'Atropurpurea Nana' ve Ilex aquifolium bitkilerinin su tüketimlerinin karșılaștırılması. Journal of Forestry Faculty of Kastamonu University, 1, 163-172.

Çepel, N., (1988). Peyzaj Ekolojisi Ders Kitabı, İstanbul Üniversitesi Orman Fakültesi Yayınları, İstanbul.

Çetin, N., \& Mansuroğlu, S., (2018). Akdeniz koșullarında kurakçıl peyzaj düzenlemelerinde kullanılabilecek bitki türlerinin belirlenmesi: Antalya/Konyaaltı örneği. Ege Üniversitesi Ziraat Fakültesi Dergisi, 55 (1), 11-18

Deveci, M., Özbucak, T.B., \& Demirkol, G., (2012). Ordu Üniversitesi kampüs alanı florasının tespiti. Akademik Ziraat Dergisi, 1 (2), 107-116.

Dirr, M.A., (2002). Dirr's Trees and Shrubs for Warm Climates: An Illustrated Encyclopedia. Timber Press, Portland, Oregon, ABD.

Dirr, M.A., (2011). Dirr's Encyclopedia of Trees and Shrubs. Timber Press, Portland, OR.

Ekmekçi, E., Apan, M., \& Kara, T., (2005). Tuzluluğun bitki gelişimine etkisi. Anadolu Tarım Bilimleri Dergisi, 20 (3), 118-125.

FAO, (2017). Water for sustainable food and agriculture, A report produced for the G20 Presidency of Germany.

Farjon, A., (2017). A handbook of the world's conifers, Brill, Leiden-Boston, ABD.

Genç, M., (2007). Otsu ve odunsu bitkiler yetiştiriciliği, Süleyman Demirel Üniversitesi Yayınları, Yayın No:76, Isparta.

Karadağ, A.A., (2008). Türkiye'deki su kaynakları yönetimine ilişkin sorunlar ve çözüm önerileri, TMMOB 2. Su Politikaları Kongresi, Ankara.

MGM, (2019). İllerimize ait genel istatistik verileri [online], Meteoroloji Genel Müdürlüğü Resmî Web Sitesi, http://www.mgm.gov.tr, [Erişim Tarihi: 21.10.2019]

Nowak, D.J., Crane, D.E., \& Stevens, J.C., (2006). Air pollution removal by urban trees and shrubs in the United States. Urban Forestry \& Urban Greening, 4 (3-4), 115-123.

Ouden, D., \& Boom, B.K., (1982). Manual of cultivated conifers: hardy in the cold-and warm-temperature zone (Third edition). Martinus Nijhoff, The Hague, Hollanda.

Önder, S., \& Polat, A.T., (2012). Kentsel açık-yeşil alanların kent yaşamındaki yeri ve önemi. Kentsel Peyzaj 
Alanlarının Oluşumu ve Bakım Esasları Semineri, 19, 73-96.

Özbucak, T.B., Kutbay, H.G., \& Özbucak, S., (2006). Ordu ili Boztepe piknik alanının florası. Ekoloji, 15 (59), 3742.

Sensoy, S., Demircan, M., Ulupınar, U., \& Balta, I., (2008). Türkiye iklimi, Turkish State Meteorological Service (DMI), Ankara.

TÜBIVES, (2019). Türkiye Bitkileri Veri Servisi [online], http://194.27.225.161/yasin/tubives/index.php, [Erişim Tarihi: 31 Ekim 2019].

Ürgenç, S., (1998). Genel Plantasyon ve Ağaçlandırma Tekniği, İstanbul Üniversitesi Orman Fakültesi Yayınları, İstanbul.

Walter, H., Harnickell, E., \& Mueller-Dombois, D. (1975). Climate diagram maps. Ind. Countries and the ecological climatic regions of the earth. Suppl. to the veg. monographs, 8 (11), 1-36.

Yener (Yayım), Ş.D., (2012). İstanbul'da Peyzaj Düzenlemelerinde Kullanılan Odunsu Bitkiler Üzerine Araştırmalar, Doktora Tezi, İstanbul Üniversitesi Fen Bilimleri Enstitüsü.
Yener, Ş.D., \& Güzel, M., (2019). Evaluation of Besiktas Abbasaga Park plants in the the context of ecological tolerans criteria, M.Zencirkıran içinde, Researches In Landscape And Ornamental Plants (s. 63-82), Gece Publishing.

Yener, Ş.D., Akdeniz, N.S., \& Zencirkıran, M., (2020). Ecological tolerance and woody landscape plants, M.Zencirkıran içinde, Trends in Landscape Agriculture, Forest and Natural Science (s. 1-20), Cambridge Scholars Publishing.

Yeşil, M., Atabeyoğlu, Ö., \& Yeşil, P., (2015). Karayollarının kent içi trafik gürültüsü düzeyine etkisi: Ordu kent merkezi örneği. Türkiye Ormancılık Dergisi, 16 (2), 177-182.

Zencirkıran, M., (2013). Peyzaj Bitkileri-I (Açık Tohumlu Bitkiler-Gymnospermae), Nobel Akademik Yayıncllık, Ankara.

Zencirkıran, M., \& Akdeniz, N.S., (2017). Bursa kent parkları odunsu bitki taksonlarının ekolojik tölerans kriterleri açısından değerlendirilmesi. Bartın Orman Fakültesi Dergisi, 19 (2), 11-19. 